\title{
Supero-medial reduction mammaplasty: a safe and reliable technique in gigantomastia and severe breast ptosis
}

Tarek Ashour ${ }^{1}$, Youssif Khachaba ${ }^{1}$, Ahmed El Naggar ${ }^{1}$

${ }^{1}$ M.D., MRCS, Lecturer of Plastic Surgery, Kasr Alainy Medical School, Cairo University, Cairo, Egypt

\section{Type of article: Surgery report}

\begin{abstract}
Reduction mammaplasty in huge breasts poses a great challenge for plastic surgeons. The classic technique is free nipple and areola grafting after breast amputation. This paper is a short technical report of reduction mammoplasty on 40 patients with severe breast ptosis (suprasternal notch to nipple $>35 \mathrm{~cm}$ ) and giganticomastia (anticipated resection of more than $1 \mathrm{~kg}$ per breast) were operated upon using superomedial pedicle technique for reduction mammaplasty. All patients were satisfied with their results aesthetically, and showed relief in their neck pain. There were no cases of total nipple-areola loss. In one breast, the nipple-areolar complex (NAC) was congested intra-operatively and free nipple grafting was done. The NAC sensation was preserved in 36 cases, and all other complications were minimal and self-limiting. The superomedial pedicle technique has proven to be a safe and reliable method for reduction mammaplasty in huge breasts. Compared to the classic free nipple and areola technique, this method showed promising results in preserving the nipple sensation and giving more pleasant natural projecting breasts.

Keywords: Mammaplasty. Mammoplasty, Plastic surgery, Breast, Egypt, Gigantomastia
\end{abstract}

\section{Introduction}

Reduction mammaplasty is a widely preformed procedure in plastic surgery, ranking the tenth most common plastic surgery procedure in the USA in 2015 (1). These procedures are renowned for having sustainable outcome, causing minimal complications and requiring no revision. Huge breasts can cause several problems to women both functionally and cosmetically. Functional problems include back and neck pain, posture deformity and recurrent infection in the inframammary region. Many reduction mammaplasty techniques have been described for patients with severe gigantomastia, however the ideal technique remains controversial. Amputation and free nipple graft remains the traditional approach for these cases $(2,3)$. A nipple grafting technique is associated with breast reduction when massive breast ptosis with a lift of the nipple-areolar complex (NAC) of $15-20 \mathrm{~cm}$ is present. However, the classic technique has many disadvantages, some of which are: limited graft take, areola hypopigmentation, and the loss of nipple projection and sensation. Moreover, complete amputation of the breast tissue that are exclusively located in the lower pole in these patients, may cause the end result of flat under-projected breasts with no upper pole fullness $(3,4)$. As a result of this methods' limitations, the inferior pedicle techniques were proposed (5-7). Yet, the latter technique resulted in the undesirable boxy breast shape and breast bottoming (8). Recently, techniques such as superior, superomedial, medial and central pedicles were used in order to overcome the disadvantages of the inferior pedicle techniques $(9,10)$, even though they were not originally described for massive ptosis of more than $35 \mathrm{~cm}$ of suprasternal notch to nipple $(\mathrm{SN}-\mathrm{N})$ distance. This study aims to evaluate the results obtained with superomedial pedicle-based breast reductions in patients with a ptosis of SN-N more than $35 \mathrm{~cm}$ and resection weight of more than $1 \mathrm{~kg}$ per breast.

\section{Corresponding author:}

Dr. Tarek Ashour, Flat 3, 1 A Wyvern road, Sutton coldfield, Birmingham, B742GA, United Kingdom.

Tel: +44.7795320950,Email: tarek_seif@hotmail.com and Tarek.ashour@nhs.net

Received: April 06, 2018, Accepted: May 28, 2018, Published: August 2018

iThenticate screening: April 16, 2018, English editing: June 12, 2018, Quality control: June 14, 2018

This article has been reviewed / commented by three experts

(C) 2018 The Authors. This is an open access article under the terms of the Creative Commons Attribution-NonCommercialNoDerivs License, which permits use and distribution in any medium, provided the original work is properly cited, the use is non-commercial and no modifications or adaptations are made. 


\section{Material and Methods}

\subsection{Setting and eligibility criteria}

This paper is a short technical report of reduction mammoplasty on 40 patients with severe breast ptosis and gigantomastia in the plastic surgery unit at Cairo University (Cairo, Egypt). Inclusion criteria were patients who had severe breast ptosis, with SN-N distance greater than $35 \mathrm{~cm}$, and an anticipated resection of more than $1 \mathrm{~kg}$ per breast.

\subsection{Data collection procedures}

Each patient's age, height, weight, and body mass index were recorded. Anthropometric measurements were recorded preoperatively, notably, the suprasternal notch to nipple distance and the nipple to inframammary crease distance. NAC sensation was tested preoperatively and postoperatively with touch and 2 points discrimination test. All patients underwent reduction mammoplasty using the superomedial pedicle technique. The operative resection weight was recorded at the time of surgery. The complications for each patient were recorded including early complications in the form of dehiscence at T-junction, nipple-areolar necrosis, hematoma, cellulitis, skin necrosis, and late complications in the form of nipple-areolar sensory loss, under-reduction, over-reduction, recurrent ptosis, scar hypertrophy, nipple retraction, contour problems and dog ears. The follow up period of the patients was at least 6 months.

\subsection{Surgical Technique}

Wise pattern reduction was carried out on all patients. The superomedial pedicle was marked preoperatively. The new nipple position was marked at the level of mid-humeral point, corresponding to the point at the level of the inframammary fold. Intra operatively, the inverted $\mathrm{V}$ area (with apex at proposed upper level of the new areola) was deepithelialized using sharp scissors, including the outer edge of the old areola outside the new areolar marking. The inframammary crease incision was deepened until the deep fascia and the breast was lifted off the pectoral fascia up to the nipple-areola level. Then the breast was lifted upwards in a perpendicular manner to the chest wall while the lower portion of the breast projected below the final inframammary crease was removed. The whole lateral breast tissue and a tangential disk of deep central tissue were excised. The NAC was held by hooks and the superomedial pedicle was undermined at $2 \mathrm{~cm}$ thickness and made progressively thicker towards the base. The pedicle was freed laterally by an incision at the lateral edge of the $\mathrm{V}$ all the way upwards to the apex of the inverted $\mathrm{V}$. The nipple and areola were then laterally rotated 60-100 degrees into their new place. A back cut of $1 \mathrm{~cm}$ at the apex of the medial limb of the $\mathrm{V}$ was done to facilitate pedicle insetting. Breasts were temporary closed with staples and checked for symmetry, and excess skin was removed at this stage to achieve best contour and projection, and to avoid any dog ears laterally and medially. The proposed areolar position was prepared by drawing a circle $4.2 \mathrm{~cm}$ in diameter starting from the apex of the $\mathrm{V}$ (representing the 12:00 o'clock mark) and the circle of skin was excised, to accommodate for the transposed areola and to avoid any undue tension. Hemostasis and final touch-ups could then be performed. Closure with 2 suction drains were placed.

\subsection{Ethics}

This study was reviewed and approved by the ethics committee at the Faculty of Medicine, Cairo University (Ref: CU 231/2010).

\section{Surgery report}

The superomedial pedicle for NAC was used in all 40 patients. Patients' ages ranged between 18-45 years (Mean: 30.97 years), height ranged between 1.53-1.82 meters (Mean: 1.68 meters), weight between 72-106 kg (Mean: $87.475 \mathrm{~kg}$ ), and body mass index ranged between $26.26-38.93 \mathrm{~kg} / \mathrm{m}^{2}$ (Mean: $31.19 \mathrm{~kg} / \mathrm{m}^{2}$ ). Four patients were diabetic. The mean suprasternal notch to nipple (SN-N) distance was on the right side $38.26 \mathrm{~cm}$ (range from 35 to 45 $\mathrm{cm}$ ), and $38.42 \mathrm{~cm}$ on the left side (range from 35 to $45 \mathrm{~cm}$ ). The distance of NAC transposition ranged between 14 $24 \mathrm{~cm}$. and the excised weight ranged from $1.2 \mathrm{~kg}$ to $2.7 \mathrm{~kg}$ on the right side and from $1.1 \mathrm{~kg}$ to $2.7 \mathrm{~kg}$ on the left side with mean value of $1.69 \mathrm{~kg}$. All patients were overall satisfied with their results aesthetically and noted relief of their neck pain post operatively. The sensation was preserved in 73 breasts, while it was lost in 7 breasts belonging to 4 patients. In one breast, the NAC was congested intra-operatively and free nipple grafting was done (Figure 1). Complications were minor and self-limiting. There were no cases of total nipple-areola loss (Figure 2). T-junction breakdown occurred in eight breasts in five patients, one of whom was diabetic. None of these patients required surgical intervention in the form of debridement or skin grafting or suturing, and all healed using simple dressings. Other complications included dog ears requiring correction on two breasts. Hematoma occurred in two breasts, and 
was resolved with conservative management. Scar widening occurred in six breasts in three patients; two of the patients were dissatisfied with the wide scars and scar revision was done.
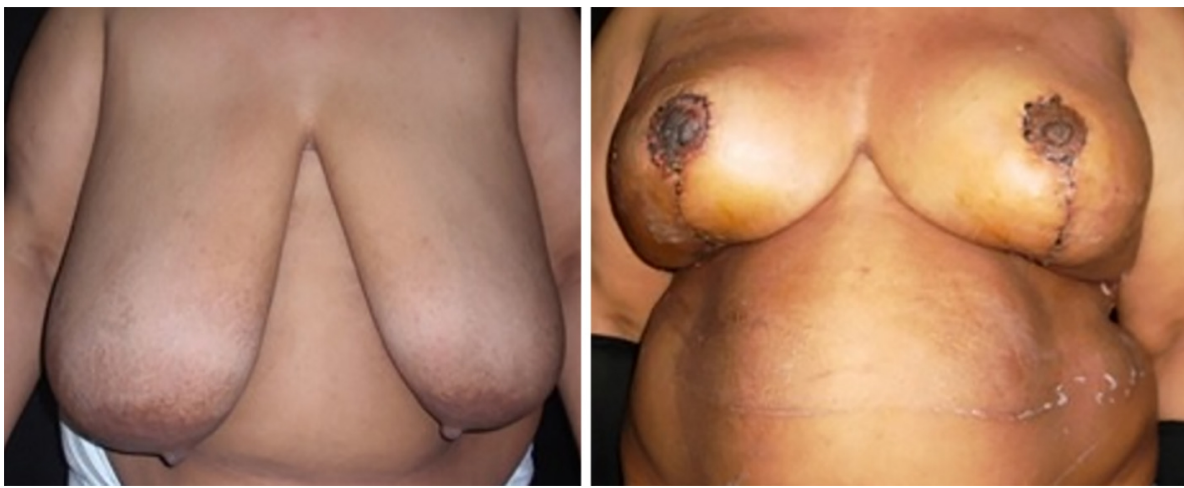

Figure 1. The preoperative (left) and early postoperative (right) photos of the patient in which free nipple and areola grafting was done on the right breast and supromedial reduction was completed on the left side

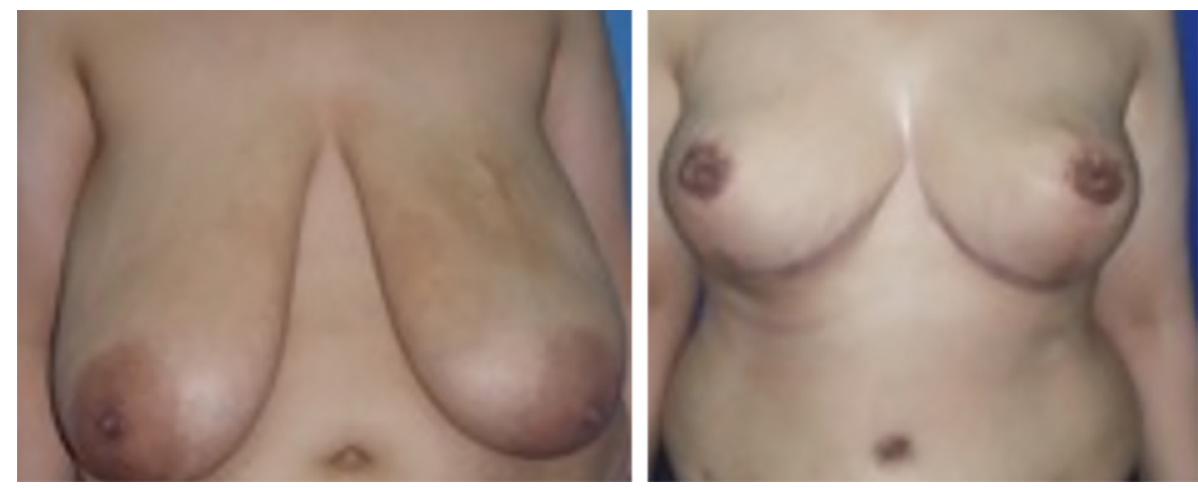

Figure 2. Preoperative anterior view of the patient (LEFT), And 6 months postoperative anterior view (right)

\section{Discussion}

The main argument against pedicle reduction in gigantomastia and severe ptosis is the possible compromise of the NAC perfusion with increasing pedicle length. Furthermore, the technical difficulties associated with handling of long pedicles poses another concern. The main concern of the first of breast reduction surgeries, described in Georgiade's Reconstructive Breast Surgery was maintaining nipple-areola viability and preventing partial breast and skin loss (11). The superomedial pedicle technique was first described by Orlando and Guthrie (12). This technique has been tested and proven to be safe in a series of studies done by Hauben (13), followed by more studies carried out by Finger et al. (14). Regardless of those efforts, the use of this technique in severe breast ptosis and gigantomastia is debatable. The standard free NAC graft reduction mammaplasty results are disappointing causing flat, non-projecting, and insensate nipples (2-4). The use of inferior pedicle technique resulted in an unsatisfactory aesthetic outcome due to bottoming and boxy breasts with flat unpleasant medial breast. In contrast, superomedial technique shows its superiority in preserving the medial and central breast tissue in continuity, and contributes towards esthetically pleasing medial fullness $(15,16)$. In this study, forty patients with severe breast ptosis (SNN distance $>35 \mathrm{~cm}$ ) and gigantomastia were operated on using superomedial pedicle technique for reduction mammaplasty with no cases of total nipple-areola loss. T-junction breakdown occurred in eight breasts in five patients, one of whom were diabetic. Dog ears occurred in two breasts and required correction. Hematoma occurred in two breasts and was resolved with conservative management. Scar widening occurred in three patients with two of them requesting revisional surgery. NAC sensation was lost in seven breasts in four patients.

Our results are similar to those of Landau et.al (9), and Costa et al. (17), where Landau's study utilized the superomedial pedicle reduction mammaplasty in 61 patients with gigantomastia in which there were no cases of total nipple-areola loss. There were 8 cases of unilateral partial areolar sloughing, $\mathrm{T}$-junction breakdown occurred in 22 breasts, and dog- ears required correction in four breasts. Although Landau et al. utilized the superomedial pedicle in gigantomastia (Excision $>1 \mathrm{~kg}$ per breast), the study did not correlate gigantomastia with breast ptosis 
where the SNN distance ranged from $24 \mathrm{~cm}$ to $44 \mathrm{~cm}(9)$. While Costa et al. utilized superior medial reduction technique in a series of 90 patients with no NAC sloughing. One patient suffered from seroma and another patient suffered from hematoma. Three patients had T-junction disruption. However, the study included only cases with nipple transposition of at least $12 \mathrm{~cm}$ and excision of at least 750 grams per breast. Central pedicle technique for reduction mammaplasty in gigantomastia was also performed by Savaci et.al in a large series of 257 patients in which the vertical scar was avoided (10). Although this technique appears to be safe, in our opinion, it may result in broad and flat breast. The wise pattern superomedial technique allows us to tighten the skin, giving more projection and natural looking breasts. Our results can be compared to the results of Reto Wettstein et al., who utilized the superior pedicle reduction technique for breast hypertrophy with massive ptosis (SNN distance $>40 \mathrm{~cm}$ ) in a series of nine patients where two of them had delayed healing at T-junction, one patient had dehiscence of the horizontal scar and one patient had superficial epidermolysis in NAC (18). Although our study included four diabetic patients, only one of them suffered from T-junction dehiscence while the other three had a smooth non-eventful postoperative course.

\section{Conclusions}

The superomedial pedicle technique is a versatile, safe and reliable method for reduction mammaplasty in huge breasts. This technique is superior to the classic free nipple and areola technique and to other reduction mammaplasty techniques as it gives a more pleasant natural projecting breasts, while preserving the nipple sensation.

\section{Acknowledgments:}

The paper was extracted from the main author's work at Cairo University Hospital. The authors would like to express their thanks to all staff members and colleagues in the Plastic Surgery Department (Cairo University) for their help and support, and special thanks to Professor Dr. Hatem Helmy, Professor of General and Plastic Surgery (Faculty of Medicine, Cairo University) for his valuable suggestions and support throughout the work.

\section{Conflict of Interest:}

There is no conflict of interest to be declared.

\section{Authors' contributions:}

All authors contributed to this project and article equally. All authors read and approved the final manuscript.

\section{References:}

1) Ogunleye AA, Leroux O, Morrison N, Preminger AB. Complications After Reduction Mammaplasty: A Comparison of Wise Pattern/Inferior Pedicle and Vertical Scar/Superomedial Pedicle. Ann Plast Surg. 2017; 79(1): 13-6. doi: 10.1097/SAP.0000000000001059. PMID: 28328638.

2) Oneal RM, Goldstein JA, Rohrich R, Izenberg PH, Pollock RA. Reduction mammoplasty with free-nipple transplantation: indications and technical refinements. Ann Plast Surg. 1991; 26(2): 117-21. doi: 10.1097/00000637-199102000-00002. PMID: 2006837.

3) Koger KE, Sunde D, Press BH, Hovey LM. Reduction mammaplasty for gigantomastia using inferiorly based pedicle and free nipple transplantation. Ann Plast Surg. 1994; 33(5): 561 -4. doi: 10.1097/00000637199411000-00017. PMID: 7857054.

4) Courtiss EH, Goldwyn RM. Reduction mammaplasty by the inferior pedicle technique. An alternative to free nipple and areola grafting for severe macromastia or extreme ptosis. Plast Reconstr Surg. 1977; 59(4): 500-7. doi: 10.1097/00006534-197759040-00004. PMID: 847026.

5) Chang P, Shaaban AF, Canady JW, Ricciardelli EJ, Cram AE. Reduction mammaplasty: the results of avoiding nipple-areolar amputation in cases of extreme hypertrophy. Ann Plast Surg. 1996; 37(6): 585-91. doi: 10.1097/00000637-199612000-00003. PMID: 8988769.

6) Gerzenshtein J, Oswald T, McCluskey P, Caplan J, Angel MF. Avoiding free nipple grafting with the inferior pedicle technique. Ann Plast Surg. 2005; 55(3): 245-9. doi: 10.1097/01.sap.0000174363.04135.b9. PMID: 16106160.

7) Lacerna M, Spears J, Mitra A, Medina C, McCampbell E, Kiran R, et al. Avoiding free nipple grafts during reduction mammaplasty in patients with gigantomastia. Ann Plast Surg. 2005; 55(1): 21-4. PMID: 15985786. 
8) Brown RH, Siy R, Khan K, Izaddoost S. The Superomedial Pedicle Wise-Pattern Breast Reduction: Reproducible, Reliable, and Resilient. Semin Plast Surg. 2015; 29(2): 94-101. doi: 10.1055/s-00351549052. PMID: 26528085, PMCID: PMC4621399.

9) Landau AG, Hudson DA. Choosing the superomedial pedicle for reduction mammaplasty in gigantomastia. Plast Reconstr Surg. 2008; 121(3): 735-9. doi: 10.1097/01.prs.0000299297.20908.66. PMID: 18317123.

10) Karacor-Altuntas Z, Dadaci M, Ince B, Karamese M, Savaci N. Central Pedicle Reduction in Gigantomastia Without Free Nipple Graft. Ann Plast Surg. 2016; 76(4): 383-7. doi: 10.1097/SAP.0000000000000388. PMID: 26954750.

11) Georgiade NG. Reconstructive breast surgery. St. Louis: Mosby; 1976: 333.

12) Orlando JC, RH Guthrie Jr. The superomedial dermal pedicle for nipple transposition. Br J Plast Surg. 1975; 28(1): 42-5. doi: 10.1016/S0007-1226(75)90149-6.

13) Hauben DJ. Experience and refinements with the supero-medial dermal pedicle for nipple-areola transposition in reduction mammoplasty. Aesthetic Plast Surg. 1984; 8(3): 189-94. doi: 10.1007/BF01597524. PMID: 6393747.

14) Finger RE, Vasquez B, Drew GS, Given KS. Superomedial pedicle technique of reduction mammaplasty. Plast Reconstr Surg. 1989; 83(3): 471-80. doi: 10.1097/00006534-198903000-00012. PMID: 2919201.

15) Iqbal A, Ellabban MG. Vertical scar reduction mammaplasty refinements. Plast Reconstr Surg. 2005; 115(3): 977-8. doi: 10.1097/01.PRS.0000153837.09566.B7. PMID: 15731732.

16) Davison SP, Mesbahi AN, Ducic I, Sarcia M, Dayan J, Spear SL. The versatility of the superomedial pedicle with various skin reduction patterns. Plast Reconstr Surg. 2007; 120(6): 1466-76. doi: 10.1097/01.prs.0000282033.58509.76. PMID: 18040175.

17) Costa MP, AW Ching, MC Ferreira. Thin superior medial pedicle reduction mammaplasty for severe mammary hypertrophy. Aesthetic Plast Surg. 2008; 32(4): 645-52. doi: 10.1007/s00266-008-9163-5. PMID: 18443850 .

18) Wettstein R, Christofides E, Pittet B, Psaras G, Harder Y. Superior pedicle breast reduction for hypertrophy with massive ptosis. J Plast Reconstr Aesthet Surg. 2011; 64(4): 500-7. doi: 10.1016/j.bjps.2010.05.018. PMID: 20580337. 